\title{
A brief intervention is sufficient for many adolescents seeking help from low threshold adolescent psychiatric services
}

\author{
Eila Laukkanen ${ }^{1 *}$, Jukka J Hintikka², Jari Kylmä3 ${ }^{3}$ Virve Kekkonen ${ }^{4}$, Mauri Marttunen ${ }^{5,6}$
}

\begin{abstract}
Background: There has been a considerable increase in the need for psychiatric services for adolescents. Primary health care practitioners have a major role in detecting, screening and helping these adolescents. An intervention entitled SCREEN is described in this article. The SCREEN intervention was developed to help practitioners to detect and screen adolescent needs, to care for adolescents at the primary health care level and to facilitate the referral of adolescents to secondary care services in collaboration between primary and secondary health care. Secondly, the article presents the background and clinical characteristics of youths seeking help from the SCREEN services, and compares the background factors and clinical characteristics of those patients referred and not referred to secondary care services.
\end{abstract}

Methods: The SCREEN intervention consisted of 1 to 5 sessions, including assessment by a semi-structured anamnesis interview, the structured Global Assessment Scale, and by a structured priority rating scale, as well as a brief intervention for each adolescent's chosen problem. Parents took part in the assessment in 39\% of cases involving girls and 50\% involving boys. During 34 months, 2071 adolescents (69\% females) entered the intervention and $70 \%$ completed it. The mean age was 17.1 years for boys and 17.3 years for girls.

Results: For $69 \%$ of adolescents, this was the first contact with psychiatric services. The most common reasons for seeking services were depressive symptoms (31\%). Self-harming behaviour had occurred in $25 \%$ of girls and $16 \%$ of boys. The intervention was sufficient for $37 \%$ of those who completed it. Psychosocial functioning improved during the intervention. Factors associated with referral for further treatment were female gender, anxiety as the main complaint, previous psychiatric treatment, self-harming behaviour, a previous need for child welfare services, poor psychosocial functioning and a high score in the priority rating scale.

Conclusions: A brief intervention carried out by a team including professionals from both primary and secondary level services was sufficient for a considerable proportion of adolescents seeking help for their psychiatric problems. Referral practices and counselling in special level services can be standardized. In the future, it will be important to develop and assess psychiatric services for adolescents using randomised controlled trials.

\section{Background}

Adolescent development with all the developmental "landmarks", such as separation from the parents, acquiring an adult personal sexual identity and the search for adult goals in life, as well as physical changes related to hormonal and sexual maturation, increase the vulnerability of adolescents to psychiatric symptoms, most commonly to

\footnotetext{
* Correspondence: eila.laukkanen@kuh.fi

'Department of Adolescent Psychiatry, Kuopio University Hospital and

University of Kuopio, Kuopio, Finland

Full list of author information is available at the end of the article
}

depressive symptoms. Epidemiological studies have shown that the incidence and prevalence of psychiatric disorders increase during adolescence, and many adult psychiatric disorders have their onset during this period [1-4]. Thus, the early detection and intervention of psychiatric symptoms and disorders may have a major impact in preventing psychiatric disorders in adulthood. Despite the relatively high prevalence of psychiatric disorders (estimated at 15 to $25 \%$ ), psychopathology in adolescents tends to be unrecognized and under-treated [5,6]. Compared to psychiatric disorders among children, disorders among

\section{Biomed Central}


adolescents are commonly undetected by parents and teachers [7].

Health care centres in primary care have a major role in detecting and screening patients with psychiatric problems in Finland. General practitioners are in a good position to provide services, but their knowledge and skills to assess and intervene in adolescent psychiatric problems are often inadequate [8-11]. The roles of primary care and secondary care services in treating adolescent psychiatric problems are often unclear $[8,9,12,13]$, leading to delays in referring youths for psychiatric evaluation. Furthermore, the threshold for a referral to psychiatric services seems high for adolescents [14].

Finnish people have universal access to health care, including adolescent psychiatric care. There has been a considerable increase in the need for psychiatric services for adolescents in Finland [14]. In order to develop and improve the health care system for adolescents who have psychosocial problems, two Finnish Health Districts in three regions (Kuopio with a population of 90 000, Lappeenranta with a population of 59000 and Imatra with a population of 30000 ) started a development project entitled SCREEN intervention (SIHTI in Finnish). SCREEN was based on collaboration between primary health care and secondary care adolescent psychiatric services. The leading principles were that the services should be easy to access without a referral, and that the psychosocial situation of the adolescents and their need for further psychiatric care would be evaluated during a brief intervention consisting of 1 to 5 sessions. The concept of SCREEN intervention is described in Figure 1.

The aims of the project were to develop problem identification and treatment practices in primary health care so that minor adolescent problems could be treated in primary care, and on the other hand to facilitate referral to secondary care services when needed in collaboration between primary and secondary health care.

The aims of this article are to describe the SCREEN intervention, present the background and clinical characteristics of youths seeking help from the SCREEN services, and to compare the background factors and clinical characteristics of those patients referred and not referred to secondary care services.

\section{Methods}

Intervention

In each region, a team including professionals from both primary care (GP, school nurse, social worker) and secondary care adolescent psychiatric services (psychologist, psychiatric nurse, consulting adolescent psychiatrist) was formed. When constituting these teams, working experience with adolescents/families and therapeutic training were prioritised. The SCREEN intervention consisted of an evaluation of the adolescents' living circumstances and assessment of the severity of problems during 1 to 5 sessions. The population and co-workers in schools and the health care system were informed about these services beforehand via announcements. Adolescents or their parents were advised to telephone or come directly to the SCREEN office.

The content of SCREEN intervention is described in Figure 2. During the first telephone contact the adolescent or parent was interviewed using a brief, semi-structured interview schedule. Based on this interview, a plan on who would participate in the first face-to-face interview (the adolescent alone or with parents) was made. Parents were asked whether they were willing to take part in the intervention. The first evaluation session (lasting 90 minutes) was conducted by two team members, and during this session the focus and time limits for intervention were decided in collaboration with the adolescent and parents. The following sessions (each 45 minutes) were carried out by one team member alone with the adolescent. Treatment schedules were individualized from a range of psychosocial interventions, including assessment and supportive intervention, brief individual psychotherapy, and psychotropic medication (e.g. antidepressive medication prescribed by a GP after consulting the psychiatrist) when appropriate. School personnel and/or child welfare personnel were also asked to participate in the intervention when appropriate. The final assessment of the adolescent's psychosocial situation and psychiatric problems as well as referral to secondary care services was made in a team session where all team members (nurses, GP, psychologist and social worker) took part and where the consulting adolescent psychiatrist also participated. A case example is presented in Figure 3.

\section{Subjects}

In total, 2071 youths consecutively entered the SCREEN services during the study period from 1 May 2005 to 30 December 2008 (34 months). Of these, 56.8\% were evaluated in Kuopio, 31.1\% in Lappeenranta and 12.1\% in Imatra. The intervention was completed by 1456 subjects $(70.3 \%)$. The study was conducted in accordance with the Declaration of Helsinki and was approved by the Ethical Committee of Kuopio University Hospital and University of Kuopio (144//2004). The data presented here were collected from health registers formed for SCREEN intervention in Kuopio and in Lappeenranta. The head doctors granted permission to use the local registers.

\section{Study Procedure}

The medical staff of the project were trained to perform all assessments in a standardized manner for evaluation and research purposes. All subjects were interviewed 
using a semi-structured checklist. This checklist was formed for clinical purposes in order to standardize the information collected from adolescents and parents. During the interview, data were collected on the adolescents' socio-demographic and socio-economic background and academic achievements, the main reason for seeking help, the person who first contacted the service, previous contacts with health or social services due to current problems, previous psychiatric treatment and previous or current contact with social services. Data on the adolescents' self-harming behaviour were also collected. Each subject was asked whether he or she had ever had suicidal thoughts (no/yes, at the moment/yes, previously) and had ever attempted suicide (yes/no). (See Table 1).

The psychosocial functioning of the subjects at entry and at the end of the intervention was assessed using the structured Global Assessment Scale (GAS) [15]. This scale is used throughout Finland in specialized adolescent psychiatric services. The GAS is a 100-point single-item observer-rating scale rating psychosocial functioning on a hypothetical continuum from excellent to extremely poor. Scores on the scale, which range from 0 (poor) to 99 (excellent), are divided into 10 ranges of functioning. A written description of each 10-point interval covers both symptom severity and social and occupational functioning. The GAS provides a summary score indicating the level of the subject's overall psychosocial functioning. All adolescents entering the SCREEN were also assessed by the team members using the structured priority criteria tool for elective secondary care adolescent psychiatric services [16]. This rating tool has been modified for use in Finland from the West Canada Waiting List Project [17]. The maximum total score of the tool is 100 points; a score of 50 is the cut-off point for specialized psychiatric services for adolescents. The priority rating tool comprises 15 items organized in four blocks: (1) symptoms and risks, (2) impaired functioning, (3) additional risk factors and (4) expected prognosis without treatment [16].

\section{Data Analysis}

The chi-squared test and Mann-Whitney U-test were used to describe the subjects and to compare male and female adolescents as well as those who did or did not complete the intervention (loss analysis). These tests 


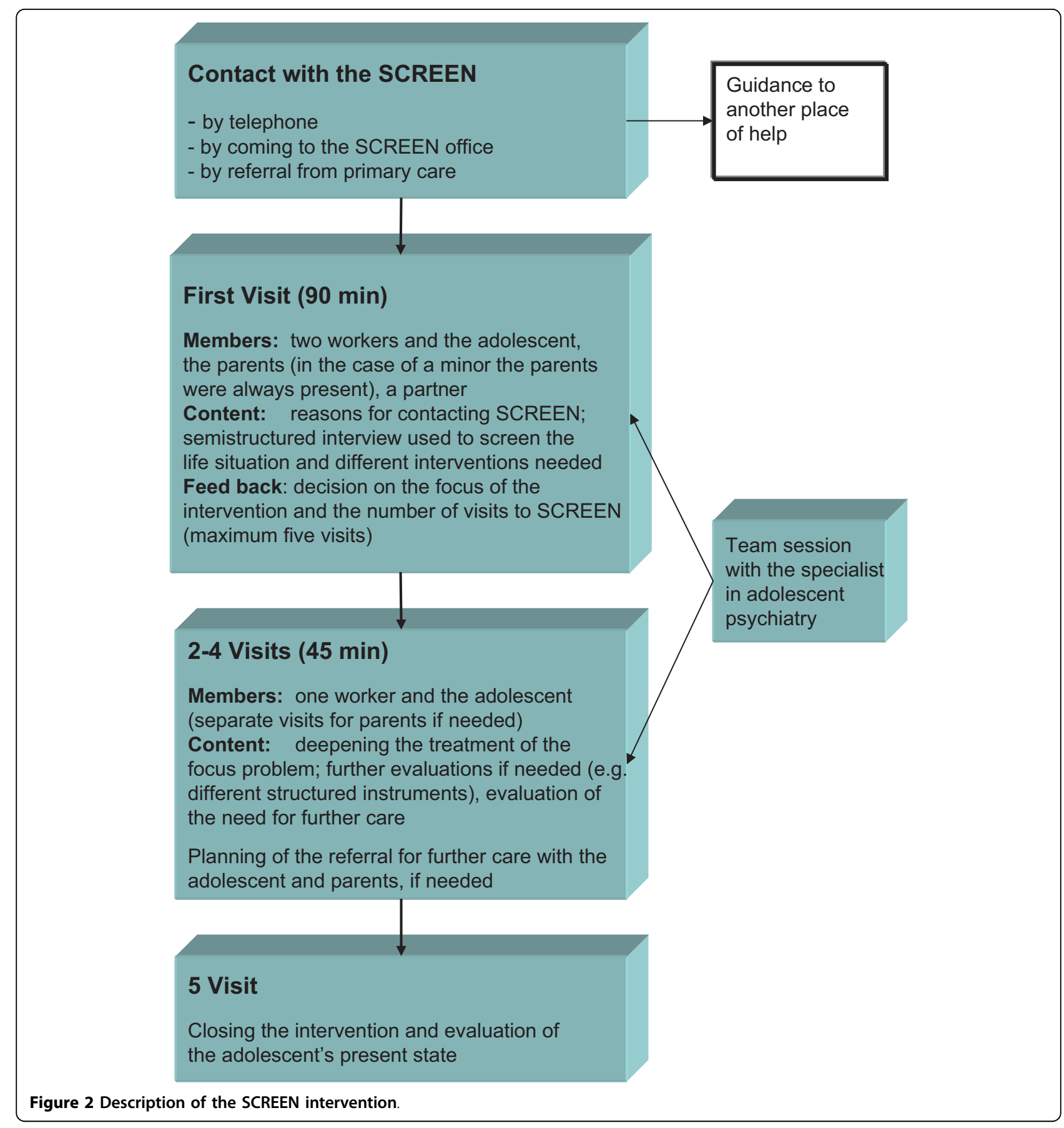

were also used to analyze differences between adolescents who did or did not need further support and treatment. Normality and homoscedasticity were visually checked.

Finally, multivariate regression models were constructed to determine which variables associated with the need for further treatment. Variables showing statistical significance $(\mathrm{p}<0.05)$ in univariate analyses as well as the study centre were included in the multivariate stepwise logistic regression models. The results were expressed as ORs (odds ratios) with their 95\% confidence intervals. All statistical analyses were performed with the statistical package SPSS for Windows 14.0.

\section{Results}

Sociodemographic and clinical characteristics at entry Altogether, 1429 (69\%) females and 642 (31\%) males entered the SCREEN services. All adolescents were 


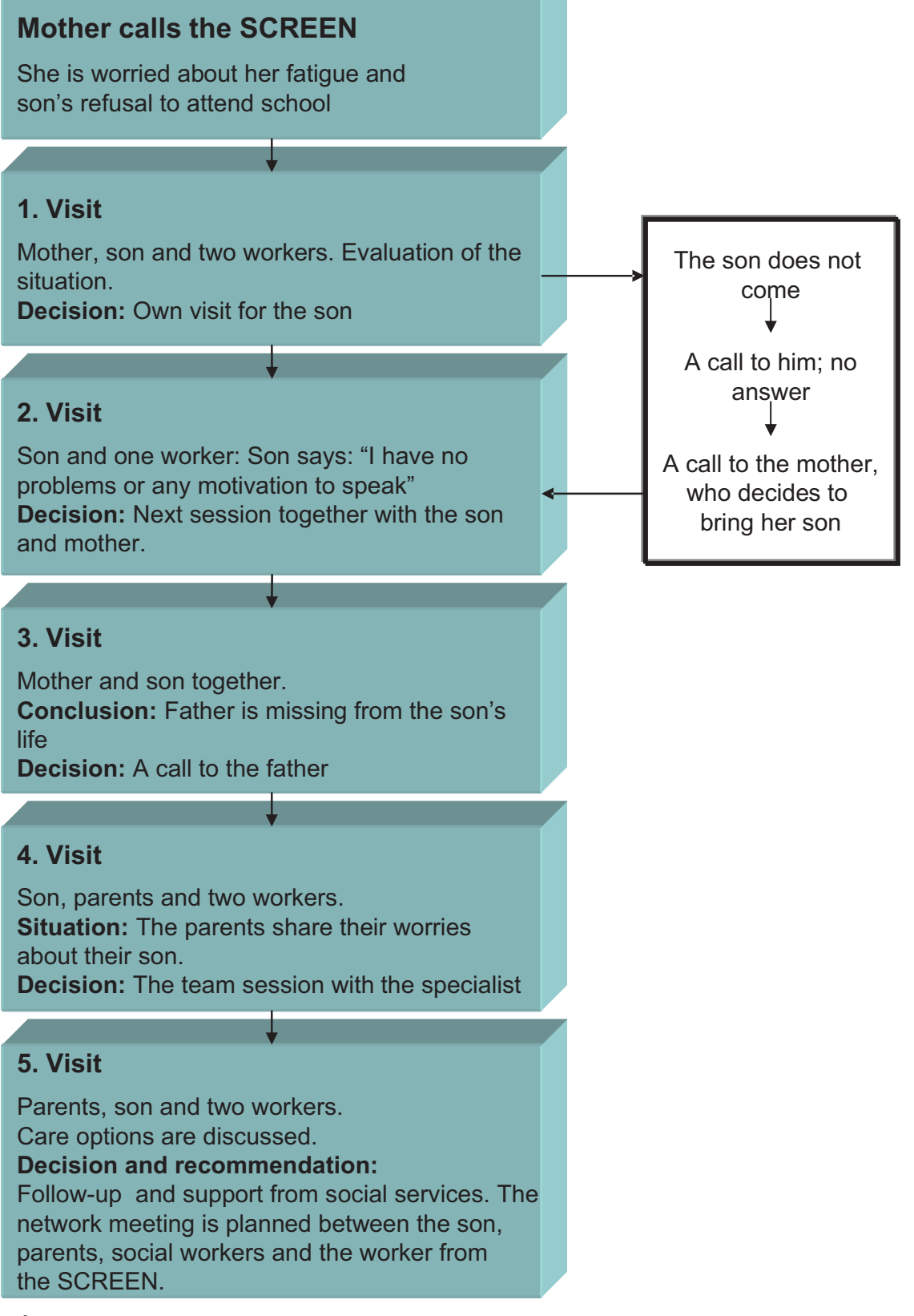

Figure 3 A case example.

white Caucasians. Female participants were statistically significantly older than male participants. The first person contacting the services was most commonly the adolescent herself among females and a parent among males. Most adolescents were students, females more commonly than males. Approximately half of the adolescents were studying in comprehensive school. Females were more commonly studying in high school or at university. Unemployment was more common among males than females. Boys more often lived with their parents than girls and, vice versa, girls more commonly lived in their own household (Table 1). Nearly half of the study subjects had divorced parents, boys more often than girls $(46.7 \%$ vs. $42.8 \%, \mathrm{p}=0.01)$.

The most common reasons for seeking help from the SCREEN services were depressive and anxiety symptoms, especially in girls. Among males, problems at school or work, and antisocial or violent behaviour also were common reasons for help seeking. Among females, problems in social relationships also were common 
Table 1 Sociodemographic characteristics of adolescents seeking help from low-threshold walk-in clinics

\begin{tabular}{|c|c|c|c|}
\hline & \multicolumn{3}{|c|}{ Study subjects } \\
\hline & $\begin{array}{l}\text { Girls } \\
\mathrm{n}=1429\end{array}$ & $\begin{array}{l}\text { Boys } \\
\mathrm{n}=642\end{array}$ & $P$ value \\
\hline Age, mean (SD) & $17.3(2.6)$ & $17.1(2.6)$ & $0.04^{1}$ \\
\hline Range & $10.9-23.7$ & $9.6-23.1$ & \\
\hline First contact from (\%) & & & $<0.001^{2}$ \\
\hline Adolescent her-/himself & 36.2 & 19.5 & \\
\hline Parent & 25.2 & 31.4 & \\
\hline School (health care) personnel & 22.3 & 20.8 & \\
\hline Psychiatric care personnel & 3.6 & 3.1 & \\
\hline Other & 12.5 & 13.7 & \\
\hline Education (\%) & & & $<0.001^{2}$ \\
\hline Comprehensive School & 47.2 & 56.1 & \\
\hline High School & 19.7 & 14.5 & \\
\hline $\begin{array}{l}\text { Vocational School/Secondary } \\
\text { education }\end{array}$ & 23.2 & 18.1 & \\
\hline College/University & 8.2 & 4.5 & \\
\hline Dropped out of school & 1.7 & 6.9 & \\
\hline Occupation (\%) & & & $<0.001^{2}$ \\
\hline Student & 87.6 & 78.7 & \\
\hline Employed & 5.7 & 6.7 & \\
\hline Unemployed & 2.6 & 5.1 & \\
\hline Other & 4.1 & 9.5 & \\
\hline Form of dwelling (\%) & & & $<0.001^{2}$ \\
\hline With parents & 57.0 & 71.3 & \\
\hline Own household & 33.9 & 18.2 & \\
\hline Other & 9.1 & 10.4 & \\
\hline
\end{tabular}

${ }^{1}$ Mann-Whitney U-test, ${ }^{2}$ Chi-squared test.

(Table 2). Eating problems as a main complaint were more common in girls than in boys $(3.5 \%$ vs. $0.3 \%, \mathrm{p}<$ 0.001 ). Over a third of all subjects had previously received psychiatric treatment, and a sixth had had contacts with child welfare services. Nearly $70 \%$ of the subjects had contacted certain services due to their current problems, most commonly school services or public health care services. Previous or current self-harming behaviour were more common among females than males. Nearly $4 \%$ of the subjects had attempted suicide during their lifetime, with no gender difference (Table 2).

The mean number of therapy sessions was 3.8 among girls and 3.5 among boys. Parents took part in the assessment more commonly among males than females. During the current assessment period, $11 \%$ of the subjects had been in contact with child welfare services. Psychosocial functioning in girls measured by the GAS score was better than that of boys, both at the time of entry and at the end of the SCREEN intervention. Accordingly, boys had higher priority rating scale scores than girls (Table 3 ). Girls successfully completed the intervention more commonly than boys $(73.1 \%$ vs. $64.2 \%, \mathrm{p}<0.001)$.

\section{Characteristics of those who did or did not complete the} intervention

Girls completed the intervention more often than boys $(73.1 \%$ vs. $64.2 \%, \mathrm{p}<0.001)$. There was a significant difference between centres in the proportion of those who completed the intervention: $68.1 \%$ in Kuopio, $71.4 \%$ in Lappeenranta and $78.0 \%$ in Imatra $(p=0.006)$. Those whose parents participated in the intervention were more often completers than others $(84.9 \%$ vs. $59.6 \%$, p < 0.001). Completing the intervention was more common among those who had sleeping problems (74.4\%), depressive symptoms (73.8\%), anxiety symptoms (78.4\%) or self-harming behaviour $(78.8 \%)$ as the main reason for contact. Conversely, completing the intervention was less common among those with school or work problems (61.3\%), substance abuse or dependence (67.2\%) or traumatic experiences $(64.6 \%)$ as the main reason for contact ( $\mathrm{p}<0.001$ for overall differences in proportions). Finally, completers had higher GAS scores at entry than non-completers (mean 56.6 (SD 9.6) versus 54.2 (SD $10.7), \mathrm{p}<0.001$ ). No difference was found in the priority rating scale total score between the groups (mean 39.6 (SD 26.9) versus 40.1 (SD 17.1), respectively; $\mathrm{p}=\mathrm{ns}$.).

\section{Characteristics of adolescents referred for further treatment}

Of the 1456 study subjects who completed the SCREEN intervention, 913 (62.7\%) were referred for further treatment by secondary care services (including psychiatric services, services for substance abuse and follow-up sessions in child welfare services). Thus, the SCREEN intervention was sufficient for $37.3 \%$ of those who completed it. The referral decision was reached in collaboration with the adolescent, parents (if participating) and the team. The proportion of those who needed referral differed between centres: $65.3 \%$ in Kuopio, $52.8 \%$ in Lappeenranta and $75.4 \%$ in Imatra (p $<0.001)$. When the subjects referred for further treatment and those not referred were compared, no statistically significant gender differences were found between the two groups, but those who required further treatment were older. A higher educational level, parents not as the persons initiating contact with the SCREEN service, and depression and anxiety as the main reason for contact were more common among those who were referred for further treatment. Moreover, previous psychiatric treatment, contacts with child welfare services, self-harming behaviour and suicide attempts were more common among those referred for further treatment. Psychosocial functioning, both at entry and at the end of the SCREEN intervention, was statistically significantly worse and the priority rating scale scores higher among those referred for further treatment (Table 4). 
Table 2 Clinical characteristics of adolescents seeking help from low-threshold walk-in clinics

\begin{tabular}{|c|c|c|c|}
\hline & \multicolumn{3}{|c|}{ Study Subjects } \\
\hline & $\begin{array}{l}\text { Girls } \\
\mathrm{n}=1429\end{array}$ & $\begin{array}{l}\text { Boys } \\
n=642\end{array}$ & $P$ value \\
\hline Previous psychiatric treatment (\%) & 30.9 & 36.6 & $0.65^{1}$ \\
\hline Previous contact with child welfare services (\%) & 13.8 & 25.2 & $0.02^{1}$ \\
\hline Previous contacts due to current problems (\%) & & & $<0.001^{1}$ \\
\hline No previous contacts & 38.9 & 30.2 & \\
\hline Psychiatric care & 5.0 & 4.4 & \\
\hline Public health care & 26.2 & 18.2 & \\
\hline Child welfare services & 6.0 & 6.9 & \\
\hline School & 26.2 & 33.3 & \\
\hline Other & 5.2 & 6.9 & \\
\hline Self-harming behaviour (\%) & 24.7 & 16.4 & $<0.001^{1}$ \\
\hline Suicide attempt (\%) & 3.9 & 4.7 & $0.58^{1}$ \\
\hline The main reason for contact (\%) & & & $<0.001^{1}$ \\
\hline Sleeping problems & 4.1 & 3.1 & \\
\hline School/Work problems & 9.5 & 21.5 & \\
\hline Depressive symptoms & 34.2 & 24.1 & \\
\hline Anxiety symptoms & 15.3 & 15.0 & \\
\hline Problems in social relationships & 16.1 & 9.3 & \\
\hline Self-harming behaviour & 2.0 & 0.8 & \\
\hline Antisocial/violent behaviour & 3.8 & 11.1 & \\
\hline Eating problem & 3.4 & 0.3 & \\
\hline Substance abuse/dependence & 2.1 & 4.8 & \\
\hline Traumatic experiences & 3.7 & 1.9 & \\
\hline Other psychiatric symptoms ${ }^{2}$ & 5.8 & 8.1 & \\
\hline
\end{tabular}

${ }^{1}$ Chi-squared test. ${ }^{2}$ Including one case with psychotic symptoms.

Factors associated with referral for further treatment

In the final logistic regression model, the statistically significant predictors of referral for further treatment among those who had completed the intervention were female gender, anxiety as the main complaint, previous psychiatric treatment, self-harming behaviour, a previous need for child welfare services, poor psychosocial functioning at entry and a high score in the priority rating scale (Table $5)$. In this group, the priority rating scale score was over 50 in $675(46.4 \%)$ subjects and $80.7 \%$ of them were referred for further treatment $(\mathrm{p}<0.001)$. The GAS score at entry was less than 50 in $243(24.0 \%)$ subjects and $90.1 \%$ of them were referred for further treatment $(\mathrm{p}<0.001)$.

\section{Discussion}

The SCREEN service reached 2071 adolescents, more females than males, during the three-year study period. Most of them were students at comprehensive school living with one or two biological parents. The most

Table 3 Psychosocial evaluation during SCREEN intervention

\begin{tabular}{|c|c|c|c|}
\hline & \multicolumn{3}{|l|}{ Study Subjects } \\
\hline & $\begin{array}{l}\text { Girls } \\
n=1429\end{array}$ & $\begin{array}{l}\text { Boys } \\
n=642\end{array}$ & $P$ value \\
\hline Number of sessions (Mean (SD)) & $3.8(2.3)$ & $3.5(2.2)$ & $0.001^{1}$ \\
\hline Number of individual sessions (Mean (SD)) & $2.9(1.9)$ & $2.5(1.8)$ & $<0.001^{1}$ \\
\hline Parents took part in the assessment (\%) & 39.0 & 50.0 & $<0.001^{1}$ \\
\hline Contact with child welfare services during assessment (\%) & 10.4 & 13.2 & $0.06^{2}$ \\
\hline Priority rating scale score (Mean $(\mathrm{SD}, \mathrm{Cl})$ ) & $38.4(24.0 ; 37.1-39.6)$ & $42.6(25.0 ; 40.7-44.6)$ & $0.001^{1}$ \\
\hline $\begin{array}{l}\text { GAS at entry } \\
(\text { Mean }(S D, C I))\end{array}$ & $56.5(9.4 ; 56.0-56.9)$ & $54.5(11.2 ; 53.7-55.4)$ & $<0.001^{1}$ \\
\hline $\begin{array}{l}\text { GAS at end } \\
(\text { Mean }(S D, C I))\end{array}$ & $60.3(11.4 ; 59.7-60.9)$ & $58.3(12.5 ; 57.4-59.3)$ & $<0.001^{1}$ \\
\hline
\end{tabular}

${ }^{1}$ Mann-Whitney U-test. ${ }^{2}$ Chi-squared test. 
Table 4 Demographic and clinical characteristics of adolescents according to referral for further treatment among those who completed the intervention

\begin{tabular}{|c|c|c|c|}
\hline & \multicolumn{3}{|c|}{ Need for further treatment } \\
\hline & $\begin{array}{l}\text { No } \\
n=543\end{array}$ & $\begin{array}{l}\text { Yes } \\
n=913\end{array}$ & $P$ value \\
\hline Age, mean (SD) & $16.9(2.7)$ & $17.4(2.7)$ & $<0.001^{1}$ \\
\hline \multicolumn{4}{|l|}{$\operatorname{Sex}(\%)$} \\
\hline Girls & 70.9 & 72.2 & $0.60^{1}$ \\
\hline Education (\%) & & $0.001^{1}$ & \\
\hline Comprehensive school & 54.5 & 47.1 & \\
\hline High School & 21.7 & 19.4 & \\
\hline Vocational School/Secondary education & 15.3 & 24.4 & \\
\hline College/University & 7.7 & 8.3 & \\
\hline Dropped out of school/Not known & 0.7 & 0.8 & \\
\hline Occupation (\%) & & $0.08^{2}$ & \\
\hline Student & 90.1 & 85.4 & \\
\hline Employed & 5.2 & 7.0 & \\
\hline Unemployed & 2.0 & 3.1 & \\
\hline Other & 2.8 & 4.5 & \\
\hline Referral (\%) & & $0.02^{2}$ & \\
\hline Adolescent & 33.7 & 32.1 & \\
\hline Parents & 36.5 & 30.7 & \\
\hline School personnel & 17.7 & 19.5 & \\
\hline Psychiatric care personnel & 1.8 & 3.6 & \\
\hline Other & 10.3 & 14.1 & \\
\hline Previous contacts caused by current problems (\%) & & $<0.001^{2}$ & \\
\hline No previous contacts & 45.7 & 34.7 & \\
\hline Psychiatric care & 3.3 & 5.9 & \\
\hline Public health care & 20.1 & 26.9 & \\
\hline Social worker & 5.5 & 6.1 & \\
\hline School & 20.8 & 20.5 & \\
\hline Other & 4.6 & 5.8 & \\
\hline The main reason for contact (\%) & & $<0.001^{2}$ & \\
\hline Sleeping problems & 5.0 & 3.4 & \\
\hline School/Work & 12.5 & 11.0 & \\
\hline Mood & 27.8 & 35.5 & \\
\hline Anxiety & 14.2 & 18.6 & \\
\hline Relationships & 18.6 & 11.3 & \\
\hline Self-harming behaviour & 0.9 & 2.3 & \\
\hline Antisocial/violent behaviour & 6.8 & 5.8 & \\
\hline Eating problem & 1.8 & 2.8 & \\
\hline Addiction & 2.9 & 2.7 & \\
\hline Traumatic experiences & 4.6 & 1.9 & \\
\hline Other psychic symptoms ${ }^{3}$ & 4.8 & 4.7 & \\
\hline Self-harming behaviour (\%) & 13.3 & 32.0 & $<0.001^{2}$ \\
\hline Suicide attempt (\%) & 0.9 & 5.4 & $<0.001^{2}$ \\
\hline Previous psychiatric treatment (\%) & 21.4 & 37.3 & $<0.001^{2}$ \\
\hline Parents took part in assessment period (\%) & 49.2 & 52.5 & $0.22^{2}$ \\
\hline Previous contact with child welfare services (\%) & 10.1 & 17.7 & $<0.001^{2}$ \\
\hline Contact with child welfare services in this assessment (\%) & 5.7 & 16.8 & $<0.001^{2}$ \\
\hline GAS at entry (Mean (SD)) & $61.7(8.3)$ & $53.5(9.0)$ & $<0.001^{1}$ \\
\hline GAS at the end (Mean (SD)) & $69.3(8.4)$ & $56.1(10.4)$ & $<0.001^{1}$ \\
\hline Priority rating scale score (Mean (SD)) & $24.3(21.9)$ & $48.6(25.5)$ & $<0.001^{1}$ \\
\hline
\end{tabular}

\footnotetext{
${ }^{1}$ Mann-Whitney U-test. ${ }^{2}$ Chi-squared test. ${ }^{3}$ Including one case with psychotic symptoms.
} 
Table 5 Factors associated with referral for further treatment ${ }^{1}$

\begin{tabular}{lll}
\hline Variable & aOR (95\% Cl) & P value \\
\hline Girls vs. boys & $1.41(1.06-1.87)$ & 0.019 \\
Anxiety as the main complaint (yes/no) & $1.59(1.13-2.23)$ & 0.008 \\
Self-harming behaviour (yes/no) & $1.75(1.26-2.43)$ & 0.001 \\
Previous psychiatric treatment (yes/no) & $1.69(1.24-2.18)$ & 0.001 \\
Previous contact with children welfare & $1.80(1.21-2.67)$ & 0.004 \\
services (yes/no) & $0.95(0.93-0.97)$ & $<0.001$ \\
GAS total score at entry & $1.03(1.02-1.04)$ & $<0.001$ \\
Priority rating scale total score & & \\
\hline
\end{tabular}

${ }^{1}$ Adjusted for the centre.

$\mathrm{aOR}=$ adjusted odds ratio. $\mathrm{Cl}=$ Confidence interval.

common reasons for contacting the services were symptoms of depression and anxiety. For about two thirds of the help-seeking adolescents, the SCREEN was their first contact with psychiatric services. The brief intervention was sufficient for approximately $40 \%$ of the contacting adolescents. Female gender, previous psychiatric or child welfare contacts, suicidal tendencies and poor psychosocial functioning characterized those subjects who were referred for specialized services.

The finding that the proportion of females entering the SCREEN service was twice that of males and that females contacted the service on their own initiative more commonly than males accords with previous research suggesting that seeking help for psychiatric problems may be easier for adolescent females than males [18]. On the other hand, male subjects more commonly lived with their parents and their educational level was lower than that of females. It is possible that the recognition of mental health problems is poorer in these families. Zachrisson et al. [19] also concluded in their study that the poor recognition of mental health problems in adolescents or their unwillingness to seek help for these problems are the major hindrances restricting treatment.

In accordance with epidemiological research on adolescent psychiatric problems [20], females in this study sought help more often for internalizing problems such as depressive or anxiety symptoms or problems in social relationships, while boys entered the SCREEN more often due to externalizing problems such as problems at school or work or antisocial behaviour. Previous studies have also suggested that girls suffering from depression are more active in seeking help than boys [21].

Although the SCREEN intervention was kept very brief, consisting of only three to five appointments, the psychosocial functioning of the subjects improved. This finding suggests that even very brief interventions combined with spontaneous remission are sufficient for many adolescent psychiatric problems, as previously reported by Andrade et al. [22].
Not surprisingly, previous psychiatric treatment, selfharming behaviour, a need for child welfare services and poor psychosocial functioning were associated with referral for further treatment. These results indicate that a brief intervention is not sufficient for adolescents with multiple, long-lasting and serious problems. It also appears that the priority rating scale for elective secondary care adolescent psychiatric services successfully screens these adolescents, as previously reported by Kaltiala-Heino et al. [16].

Female gender was a predictor for needing further psychiatric services. Many factors could explain this result. Boys had more externalising symptoms than girls and they more often came on the initiative of their parents. One explanation may also be that the SCREEN intervention was not successful in motivating boys with externalizing symptoms to use adolescent psychiatric services. It seems easier to offer referral for psychiatric services for a girl who has internalising symptoms and is motivated to seek treatment.

The study sample was a large, unselected sample from two Finnish health districts, representing adolescents from urban and semi-urban areas. Data were collected via a semi-structured clinical interview and reliable structured ratings. The main limitation was the lack of use of a structured diagnostic interview, precluding analysis of formal psychiatric diagnoses of subjects in need of further treatment. Generalization of the results to other cultures should take into account possible differences in health care systems. Future analyses of these data need to include a follow-up of youths referred and not referred for further treatment after the brief intervention.

\section{Conclusions}

A brief intervention, tailored individually according to the needs of each adolescent, was sufficient at this stage of life for a considerable proportion of those contacting the SCREEN service. The decision on referral to further treatment in cooperation with the adolescent/parent could be appropriately made during the intervention. Bringing together knowledge from specialist level adolescent psychiatric services and primary care services seems to have been successful. It appears possible and appropriate to assess and in many cases to treat adolescent psychiatric problems in primary health care without referral to a specialist. The SCREEN service most probably lowers the threshold for seeking help and helps to avoid youths being labelled for using mental health services [21]. The intervention also shows that referral practices and counselling in specialist level services can be standardized. However, it must be noted that only after a randomised, controlled study can final conclusions be made about the effect of intervention. In the 
future it will be important to develop psychiatric services for adolescents at all levels of the health care system in order to intervene early in psychiatric disorders. In particular, boys with externalizing problems are a great challenge for the health care system.

\section{Funding}

This SCREEN intervention and study received funding from the Ministry of Social Affairs and Health of Finland and Kuopio University Hospital.

\section{Acknowledgements}

We warmly acknowledge all our colleagues for their contribution to the SCREEN intervention and research project. In particular, Head Doctor Antti Henttonen, Nursing Director Teija Kemppi and Medical Director Matti Pietikäinen helped in collecting the study data.

\section{Author details}

'Department of Adolescent Psychiatry, Kuopio University Hospital and University of Kuopio, Kuopio, Finland. '2Department of Psychiatry, Paijat-Hame Central Hospital and University of Tampere, Lahti, Finland. ${ }^{3}$ Department of Health Sciences, University of Oulu, Senior Lecturer, Department of Nursing Science, University of Tampere, Finland. ${ }^{4}$ Department of Adolescent Psychiatry, Joensuu Central Hospital, Finland. ${ }^{5}$ Department of Adolescent Psychiatry Helsinki University Hospital and University of Helsinki, Finland. ${ }^{6}$ Mental Health and Substance Abuse Services, National Institute for Health and Welfare, Helsinki, Finland.

\section{Authors' contributions}

EL planned the intervention, participated in the planning of the study and in the preparation and writing of the manuscript; $\mathrm{JH}$ performed the statistical analysis of the study and participated in writing the manuscript; JK participated in the planning of the project and in the preparation and writing of the manuscript; VK participated in the preparation and writing of the manuscript; MM participated in the writing of the manuscript.

\section{Competing interests}

The authors declare that they have no competing interests.

Received: 21 April 2010 Accepted: 6 September 2010 Published: 6 September 2010

\section{References}

1. Paus T, Keshavan M, Giedd JN: Why do many psychiatric disorders emerge during adolescence? Nature Reviews Neuroscience 2008, 9:947-957.

2. Roberts RE, Attkisson CC, Rosenblatt A: Prevalence of psychopathology among children and adolescents. American Journal of Psychiatry 1998, 155:715-725

3. Kim-Cohen J, Caspi A, Moffitt TE, et al: Prior juvenile diagnoses in adults with mental disorders: developmental follow-back of a prospective longitudinal cohort. Archieves of General Psychiatry 2003, 60:709-801.

4. Verhulst FC, van der Ende J, Ferdinand RF, Kasius MC: The prevalence of DSM-III-R disorders in a national sample of Dutch adolescents. Archives of General Psychiatry 1997, 54:329-336.

5. Zachrisson HD, Rodje K, Mykletun A: Utilization of health services in relation to mental health problems in adolescents: a population based survey. BMC Public Health 2006, 6:34.

6. Wittchen HU, Nelson CB, Lachner G: Prevalences of mental health disorders and psychosocial impairment in adolescents and young adults. Psychological Medicine 1998, 28:109-126.

7. McGee R, Feehan M, Williams S: Long-term follow-up of a birth cohort. In The epidemiology of child and adolescent psychopathology. Edited by: Verhulst FC, Koot HM. Oxford, New York, Tokyo: Oxford Univ Press; 1996:366-383.

8. Hafting M, Garlov I: "You may wade through them without seeing them": general practioners and their young patients with mental health problems. Nordic Journal of Psychiatry 2009, 63:256-259.
9. Rushton J, Bruckman D, Kelleher K: Primary care referral of children with psychosocial problems. Archives of Pediatrics and Adolescent Medicine 2002, 156:592-598.

10. Joukamaa $M$, Lehtinen $\mathrm{V}$, Karlsson $\mathrm{H}$ : The ability of general practitioners to detect mental disorders in primary health care. Acta Psychiatrica Scandinavica 1995, 91:52-56.

11. Macdonald W, Bradley S, Bower $P$, et al: Primary mental health workers in child and adolescent mental health services. Journal of Advanced Nursing 2004, 46:78-87.

12. Bower $P$, Garralda $E$, Kramer $T$ : The treatment of child and adolescent mental health problems in primary care: a systematic review. Family Practice 2001, 18:373-382.

13. Bryce G, Gordon J: Managing child and adolescent mental health problems: the views of general practitioners. Health Bulletin (Edinb.) 2000, 58:224-226.

14. Laukkanen E, Pylkkänen $\mathrm{K}$, Hartikainen B, et al: A new priority in psychiatry: Focused services for adolescents. Nordic Journal of Psychiatry 2003, 57:37-43.

15. Endicott J, Spitzer RL, Fleiss JL, et al: The Global Assessment Scale. Archives of General Psychiatry 1976, 33:766-771.

16. Kaltiala-Heino R, Frojd S, Autio V, et al: Transparent criteria for specialist level adolescent psychiatric care. European \& Child Adolescent Psychiatry 2007, 16:260-270.

17. Smith DH, Hadorn DC, Screening Committee of The Western Canaca Waiting List Project: Lining up for children's mental health services: A tool for prioritizing waiting lists. Journal of the American Academy of Child and Adolescent Psychiatry 2002, 41:367-376.

18. Aalto-Setälä T, Marttunen M, Tuulio-Henriksson A, et al: Psychiatric treatment seeking and psychosocial impairment among young adults with depression Journal of Affective Disorders. 2002, 70:35-47.

19. Zachrisson HD, Rödje $K$, Mykletun A: Utilization of health services in relation to mental health problems in adolescents: a population based survey. BMJ 2006, 6:34.

20. Rutter M, Caspi A, Moffitt TE: Using sex differences in psychopathology to study causal mechanisms: Unifying issues and research strategies. Journal of Child Psychology and Psychiatry 2003, 44:1092-1115.

21. Sen B: Adolescent propensity for depressed mood and help seeking: race and gender differences. The Journal of Mental Health Policy and Economics 2004, 7:133-145.

22. Andrade AR, Lambert EW, Bickman L: Dose effect in child psychotherapy: Outcomes associated with negligible treatment. Journal of the American Academy of Child and Adolescent Psychiatry 2000, 39:161-168.

\section{Pre-publication history}

The pre-publication history for this paper can be accessed here: http://www.biomedcentral.com/1472-6963/10/261/prepub

\section{doi:10.1186/1472-6963-10-261}

Cite this article as: Laukkanen et al:: A brief intervention is sufficient for many adolescents seeking help from low threshold adolescent psychiatric services. BMC Health Services Research 2010 10:261.

\section{Submit your next manuscript to BioMed Central and take full advantage of:}

- Convenient online submission

- Thorough peer review

- No space constraints or color figure charges

- Immediate publication on acceptance

- Inclusion in PubMed, CAS, Scopus and Google Scholar

- Research which is freely available for redistribution

Submit your manuscript at www.biomedcentral.com/submit
Biomed Central 